\title{
ASSESSMENT OF THE IMPACTS OF NEW MINING TECHNOLOGIES: RECOMMENDATIONS ON THE WAY FORWARD
}

\author{
HORATIO SAM-AGGREY \\ Department of Lands, Government of the Northwest Territories, Canada
}

\begin{abstract}
Rapid growth in technological innovation in the mining sector is having a fundamental impact on the mining landscape. Innovation fuelled by automation, digitization, and electrification have led to the introduction of autonomous vehicles, automated drilling and tunnel boring systems, drones, and smart sensors. While these new technologies could contribute to improved profit margins, reduced greenhouse gas emissions, and improved worker health and safety, they could also have significant impacts on local employment levels, skills creation, and local content in mining projects. Emerging technologies may also give rise to new types of environmental and occupational health problems, due to for example, the emissions of nanomaterials. Hence, new technologies may warrant a reassessment of project impact assessment categories, as some categories that may be relevant for assessing new technologies may not exist yet, whereas some that do exist may not be relevant. Hence, organisations conducting project assessments should prepare and respond to these technological shifts in the mining sector. This paper highlights some technological innovations and their potential socio-economic and environmental impacts on communities. It also assesses the impact of innovation on the environmental assessment and regulatory processes for mines. Recommendations on ways of assessing the biophysical, environmental and socio-economic impacts of new technologies are outlined.

Keywords: automation, digitization, mines, Aboriginal, UNDRIP, employment, impact benefit agreements, socio-economic agreements, innovation, environmental assessment, regulation.
\end{abstract}

\section{INTRODUCTION}

Declining commodity prices and declining profit margins have made it pivotal for mining companies to reduce their cost of operations, by reducing labour, energy, and other expenses. As new and remaining deposits become increasingly remote, deep, and difficult to access, new or innovative approaches are required. Hence, for companies to improve their productivity and remain competitive, there is a need for the adoption of innovative technologies [1]-[3].

Rapid advances in technological innovation, as manifested in the increasing automation, digitization, and electrification of operations, are significantly changing many aspects of the mining industry. The World Economic Forum (WEF) estimates that autonomous machines could add up to USD 56 billion in value to the industry by 2025 , due the fact that these machines enable mines to operate for longer hours, at high levels of productivity and with lower personnel costs [3]. The WEF also predicts that digitization, through improved health and safety, could save an estimated 1,000 lives and avoid 44,000 injuries [3]. Despite these seemingly positive forecasts, it is unclear what impacts these technological advances would have on the relationship between mining companies and potentially impacted communities close to mines. In most cases, these communities are heavily dependent on the social and economic benefits created by the nearby mines. In this light, governments, communities and other stakeholders would have to respond to these technological shifts in the sector, if they are to reap the financial benefits generated by innovations in the mining sector.

This paper highlights some mining technological innovations and their potential socio-economic and environmental impacts on Aboriginal communities in northern Canada. The paper also outlines some occupational safety concerns raised by these innovations. It 
examines many of the technologies and their potential effects. This is intended to facilitate the understanding of how the impacts of these technologies can be potentially distributed and experienced.

The Environmental Assessment (EA) and regulatory processes are important parts of government oversight of new and operating mines. The paper also assesses the implications of these technological changes on the EA and regulatory processes for mines.

Section 2 of this paper provides a synopsis of some of the significant innovations in the mining sector. Section 3 discusses the impacts of these new technologies on Aboriginal communities, focusing on local employment, and local agreements, such as the Impact Benefit Agreements (IBAs) and Socio-economic Agreements (SEAs). The ramifications of these technological innovations on the formal EA and regulatory processes are assessed in Section 4, while Section 5 provides concluding statements and recommendations on ways that governments, regulatory agencies and Aboriginal communities can mitigate some of the negative impacts of some of these new technologies.

\section{SOME MAJOR MINING TECHNOLOGICAL INNOVATIONS}

Autonomous vehicles, including haul trucks, loaders and long-distance haul trains, automated drilling and tunnel boring systems; drones; autonomous equipment monitoring wearable, smart sensor technologies; and electric-powered trucks, are some of the innovative technologies rapidly gaining ground in the mining sector [4]. 3D metal printing and "nanobots" (mini robots programmed to burrow deep into the earth to target valuable minerals) are other technological innovations that are likely to be deployed in the mining sector in the near future [3]. This section outlines some mining technological innovation in the form of automation, digitization and electrification of operations.

\subsection{Automation}

Rio Tinto's iron ore mines in the Pilbara region of Western Australia, some of the most automated mines in the world, exemplify the mining industry's automation drive [5]. Rio Tinto, owner of Diavik diamond mine in northern Canada, is the global industry leader in mining automation, owning and operating the world's largest autonomous haulage systems (AHS) [5]. The AHS includes automated trucks and fully autonomous, long-distance railway, at its iron ore mine sites in Australia. The AHS trucks can operate nearly 24 hours per day, every day of the year [5]. The autonomous fleet outperforms the manned fleet by an average of $14 \%$ and has reduced operating costs by $13 \%$ [6]. The company also operates autonomous drill systems (ADS) used to drill production blast holes [5]. These automated drill rigs are capable of drilling blast patterns more quickly and accurately than any human or human operated equipment. All of these automated machines are controlled remotely by 400 people from an operations centre in Perth [5].

The adoption of AHS is dependent on many factors, including the mine design, available local infrastructure, topography, the size, scale, and longevity of mining operations, and the remoteness of mining operations [7]. Despite these factors, as costs of these technologies continue to drop, and as ongoing testing of these technologies show productivity improvements and the resulting increased profit margin, there will be considerable pressure on other mines around the world to adopt these technologies.

While there may be some scepticism about the applicability of AHS in northern Canada because of the difficulties of access to ports, less developed local infrastructure and problems of cold weather, Rio Tinto is a major operator in Canada's north, hence it is not far-fetched to expect similar changes in Canada in the near future. 


\subsection{Digitisation of mines}

Advances in sensing and monitoring systems are enabling a connected network of low cost, highly capable sensors to capture data in real time, thereby enabling integrated planning, control and operational decision support. These sensors are increasingly being fitted on various machinery and equipment to provide real-time data that can be analysed to facilitate quicker decision-making relating to occupational safety, equipment performance and strategic investment, by mining companies.

Goldcorp's remote Éléonore gold mine in northern Quebec is using smart sensors to facilitate the collection of real-time data on the performance of its equipment and infrastructure, as well as the location of its personnel. This capability is facilitated by the installation of a multiservice, secure IP network throughout the mine, enabling full Wi-Fi connectivity underground [4]. All workers, vehicles and other heavy equipment are fitted with sensors, which transmit the person or equipment's unique ID number and location to the operations centre via the Wi-Fi network. Sensors integrated into the vehicles also send information about the engine's functioning and systems, and issue alerts when maintenance is needed [4].

\subsection{Mine innovation and battery electrification}

Driven by the potential for significant cost reduction, lowered carbon emissions, and improved worker health benefits, the mining industry is gradually deploying battery electric vehicles (BEVs) and battery-operated equipment for mining. BEVs are likely to reduce mines' use of diesel-operated vehicles. When equipped with rapid chargers, or replaceable batteries, battery operated automated drill rigs could facilitate uninterrupted mining operations. Also, when equipped with sensors, these rigs are also capable of drilling blast patterns more accurately than any human or human operated equipment [4].

The use of battery-operated equipment and vehicles is critically important, given that many mines depend on diesel operated equipment for their operations and for ventilation of underground mines. The negative effects of diesel particulates on humans and the environment is well documented [8]. The use of battery-operated equipment, unlike their diesel or gas counterparts, does not produce harmful exhaust fumes, hence potentially less harmful to humans and the environment [9].

Goldcorp's remote Borden gold mine in northern Ontario became Canada's first all-electric underground mine in 2019, featuring leading-edge health and safety controls, digital mining technologies and processes, and a battery-powered fleet of low-carbon energy vehicles (load-haul-dump loaders and personnel carriers) drills, bolters [10].

\subsection{Mine innovation technologies are mutually reinforcing}

The automation, digitisation and the battery electrification of mines are mutually reinforcing trends. Advancements in sensor and GPS technologies make automation more practical and efficient. Automation reduces operations cost and makes it more economical for the deployment of larger numbers of these vehicles. Similarly, the higher the number of automated trucks and equipment operating, the more it makes economic and occupational sense to deploy battery-operated vehicles. Digitisation also facilitates the use of battery-operated equipment because it makes it possible for different types of sensors to be deployed on this equipment. Given these interconnections, it is difficult to separate the effects of one form of innovation from the other two. Hence, the successful convergence of these three innovations is vital to the future of innovation in the mining industry. 


\section{IMPACTS OF INNOVATIVE MINING TECHNOLOGIES ON ABORIGINAL COMMUNITIES}

As noted in the previous section, although technological innovation offers many competitive advantages to mining companies, the relationship between mining companies and potentially impacted neighbouring communities, could be significantly affected by the deployment of some of these new technologies. While recognising that the specific effects of the introduction of a new technology into a mine will depend on many factors such as location, the type of technology implemented, and the speed of deployment of the new technology, evidence suggests that on balance, the effects of automation on neighbouring communities are likely to be negative [11].

There is a correlation between the location of Aboriginal communities, mining activities and known mineral deposits. In fact, Natural Resources Canada (NRCan) estimates that approximately 1200 Aboriginal communities are located within 200 kilometres of mining operations [12]. This section focuses on the potential impacts of these technologies on Aboriginal employment, local economic activities, IBAs and SEAs.

\subsection{Employment}

In Canada, in many northern Aboriginal communities, employment in mines are often one of the few opportunities for peoples to engage in paid employment [13]. Relative to other industries, the Canadian mining industry is an important employer of Aboriginals, providing jobs to over 16,600 individuals in 2016 (the year for which latest data is available). This makes the industry, proportionally, the largest employer of Aboriginals in Canada [14]. The largest share of Indigenous employment was in the upstream mining subsector where Indigenous peoples accounted for $12 \%$ of the industry's labour force, which is almost three times the all-industry average of $4 \%$ [14].

Available evidence suggests that Aboriginals are more vulnerable to job losses due to automation because they are disproportionately employed in manual and semi-skilled jobs in the mining sector [15]. Increased mine automation is likely to lead to a decrease overall labour requirement, thereby reducing employment in the sector. Drilling, blasting, and truck driving typically constitute over $70 \%$ of mining employment [16]. These routine jobs are usually the target for automation, hence job losses due to innovation are more likely to impact those workers who are already highly vulnerable in the work force.

In 2019, the Aboriginal unemployment rate in Canada was almost double the national rate $(10.1 \%$ versus $5.7 \%)$ [17]. In the same year, in the Northwest Territories (NWT), the employment rate for Aboriginals was $48.3 \%$, while those of non-Aboriginal Canadians was $80.9 \%$ [18], representing a gap of $32.6 \%$. Declining Aboriginal employment in the mining sector would not only disrupt the positive trend of increased Aboriginal employment in the sector, but also potentially exacerbate the employment and unemployment gap between Aboriginals and non-Aboriginals.

The effects of technological innovation on jobs is not likely to be homogenous. For example, unlike automation, the deployment of smart sensors and machine learning could boost productivity without significant job losses. Additionally, the introduction of a similar technology in different settings could have different outcomes; and the speed at which technologies are rolled out could also impact jobs differently [19]. New technologies may make some jobs redundant, but also create new jobs requiring different skills. For example, automation will likely result in the shifting of skill profiles from truck drivers, to employees with data processing and digital literacy skills [20]. For employees, the ability to transition, upskill, cross-skill and reskill will be essential. Workers and potential workers from nearby 
communities may be challenged to fill these positions, given the comparatively lower levels of Aboriginal education, literacy and skills sets in Canada [20]. Also, many of the new jobs will be in operation centres located miles away from mine site in larger cities. In such cases, employees (or job seekers) from nearby communities would have to relocate (if they qualify), a commitment not everyone can make. It is likely that Aboriginal employment will be impacted negatively by automation and other technological developments.

\subsection{IBAs and SEAs}

IBAs are negotiated agreements between project proponents and Aboriginal communities, to mitigate the various social, economic, and biophysical impacts of extractive activities on one or more Aboriginal groups [21], [22]. However, because most IBAs are confidential agreements between project proponents and Aboriginal communities, it is difficult, for authorities to monitor the implementation of the provisions of these agreements.

IBAs are designed to not only address the adverse effects of development activities on potentially impacted Aboriginal communities by outlining mitigatory measures, but to also provide benefits or some compensation for these activities. These benefits normally include revenue sharing, equity stakes in the mining companies, employment quotas for community members and business development provisions such as quotas for contracting and subcontracting opportunities for the purchase of mine-related goods and services from Aboriginal-owned firms. Community wellbeing provisions, such as education and social programs and physical infrastructure are also common features of these agreements. There are about 410 of such agreements in Canada [23].

A key aspect of IBAs is project certainty provisions, which provide assurance that in exchange for the mitigation of social and environmental impacts and the provision of benefits to the affected community, the community will not oppose the project. Hence, if the IBA provisions are not legally challenged, IBAs provide the project proponent with the Social License to Operate (SLO) from the affected Aboriginal communities.

Another important agreement in the mining landscape in northern Canada is the SEAs. In N.W.T., when a major resource development project is going through the approval process, the territorial government asks the proponent to provide an outline of its programs aimed at providing socio-economic benefits to northerners and monitoring some of the effects of their project on potentially impacted communities. SEAs are agreements between the territorial government, Aboriginal governments and organizations representing potentially impacted communities, and the proponents of major projects [24].

SEAs typically include company commitments to employment and business opportunities, cultural and community wellbeing. The GNWT oversees the implementation of these agreements, tracking progress on the goals of the SEAs and coordinating its efforts under each agreement. There are five SEAs in the NWT [24].

SEAs are somewhat identical to IBAs and can be considered as an amalgamation of all the IBAs signed by a proponent with potentially impacted Aboriginal communities, except that SEAs target all northerners, not only Aboriginals.

The importance of IBAs and SEAs to the socio-economic sustenance of local Aboriginal communities cannot be underestimated. Since 1996, NWT diamond mines have spent approximately $\$ 14.6$ billion (about $70 \%$ of their total procurement) with northern businesses. Of this amount (about $\$ 6.5$ billion (or $31 \%$ of total procurement) has been spent with northern Indigenous businesses [24].

Since IBAs are confidential private agreements, there is a scarcity of research on their impacts on communities. Nevertheless, the scanty evidence available suggests that 
communities with IBAs tend to have lower unemployment rates, higher income levels and better housing facilities, compared to those without IBAs [25].

The predicted acceleration in mine automation could negatively impact the provisions of these IBAs and SEAs. According to Cosbey et al. [11] automation-related losses in local procurement of goods and services, salaries and wages, indirect and induced impacts, leads to a decline in the contribution of the mines to local host economies by between $8.5 \%$ to $19 \%$ in OECD countries. Holcombea and Kemp [16] also assert that mine automation could lead to a decline in Aboriginal employment in the sector. This is due to the fact that Aboriginals are overrepresented in segments of the mining work force that are more likely to be automated.

It is key to assert that the potential effects of mining technological innovation on IBAs and SEAs are not uniform. Many IBAs do have provisions for revenue sharing, and the payment of royalties to communities. Additionally, many proponents are increasingly offering equity stakes to communities as part of their IBAs. It is worth noting that equity provisions are a more recent addition to IBAs and it is unlikely that a majority of IBAs have such provisions. For IBAs with the aforementioned provisions, increases in productivity and profitability due to mining innovation could increase the financial benefits accruing to communities from royalties and equity in these mining companies. The question then becomes - do these monetary benefits from royalties, revenue sharing, and equity stakes outweigh the costs of automation (job loss, declines in contracting and subcontracting opportunities)? It is highly unlikely that these increased revenues derived from increased profitability would outweigh the losses accrued due to automation [11].

Another potential impact of the implementation of new technologies with implications for IBAs and SEAs is the shortening of the lifespan of mines. Innovative mining technologies allow companies to operate with greater speed and efficiency, producing higher yields, processing more raw materials (depending on the mineral) and potentially reducing the extraction period of a mine (given that mineral resources are finite) [26]. The socio-economic consequences of a shortened mine lifespan from 30 years to 15-20 years could be significant for small communities. A shorter mine lifespan could potentially impact the duration of IBAs and SEAs and their accompanying socio-economic benefits, potentially leaving communities to find other sources of livelihood earlier than planned.

The deployment of innovative technologies could have significant negative impacts on the fulfilment of the commitments under these agreements. Automation and other mining related innovations raise pertinent questions for the parties to IBAs and SEAs. In an era of increasing automation, can these agreements adapt to rapidly changing technological conditions in the industry? Are Aboriginal companies equipped to provide the goods and services required for the new technologies to be deployed in mines? Do locals of potentially impacted communities have the opportunities to acquire the skills needed for the high-tech mines?

\section{IMPLICATIONS OF TECHNOLOGICAL INNOVATION FOR ENVIRONMENTAL ASSESSMENT AND REGULATION OF MINES}

Environmental assessment is a process to predict the environmental effects of proposed initiatives before they are carried out [27]. Impact assessment, a key feature of the EA process, typically involves evaluating the potential environmental, economic and social impacts of a project, based upon experience with similar projects and existing knowledge.

The development of new mining technologies is progressing at a rapid rate and guidelines and regulations often cannot develop at the same pace, thereby creating the "pacing problem" [28]. The "pacing problem" refers to the gap between technological developments and the mechanisms intended to regulate them. Hence, for agencies responsible for EA and regulation of mines, establishing systematic processes for the review and acceptance of proposed new 
technologies, to identify and address associated risks, will not only support technological innovation but also ensure safe and environmentally responsible operations.

This section assesses the implications of mining technological innovation on the EA and regulatory processes in the following areas - (a) Knowledge gap about new technologies; (b) Cybersecurity; and (c) IBAs and SEAs as markers of socio-economic benefits.

\subsection{Knowledge gap about new technologies}

One of the biggest challenges to assessing the impacts of new technologies during the EA and regulatory phases of mines is the lack of an adequate sample or reliable data on the effects of these technologies [29]. This knowledge gap could limit the extent to which authorities can perform due diligence to protect the impacted communities from the potentially harmful effects of new technologies.

As an example, new and emerging technologies may give rise to new types of environmental and occupational health problems, precipitated by the emissions of nanomaterials (NMs) [30]. The potential of new mining technologies to release NMs into the air, soil and water is still under research. Similarly, the toxicological behaviour and mechanisms of biological reactivity of NMs that are released into the air, soil or water and ingested by humans and animals remain largely unknown [31]. The lack of adequate information on the effects of these new technologies could lead to a situation where government decision makers would have to rely heavily on the technical information (which may be biased) provided by the project proponent, because they may not have independent and objective knowledge about the technology in question.

The impacts of these new mining technologies on the regulatory process demonstrates the need for the responsible authorities to acquire varied expertise in technologies, in order to facilitate their work. In some cases, the knowledge or expertise relating to these new technologies may not be available because of their novelty, hence the onus is on impact assessment and regulatory organizations to collaborate with universities, technology providers and proponents to build up their capacity to effectively assess the impacts of these new technologies. These technologies may also require regulatory authorities to "think outside the regulatory box". Employing an overly prescriptive approach may not be suitable for the deployment of innovative technologies.

\subsection{Cybersecurity and data protection}

As the collection and analysis of data from smart sensors and big data become more pervasive in the operation of mines, cybersecurity and data protection are becoming crucial topics. Automated trucks introduce vulnerabilities for widespread cyber-attacks, including the potential for the vehicles to be cyber-hijacked and used as weapons in attacks against different targets, raising national security concerns. Another danger is hackers being able to remotely control ventilation fans and other health and safety related accessories in mines, thereby creating occupational safety concerns for companies and regulators. Cybersecurity becomes a matter of critical concern for impact assessors and regulators as they seek to protect the mining infrastructures from cyber threats.

While it may not be possible to prevent all security breaches, regulators will need to ensure that companies have good cybersecurity practices in place and are able to react to breaches quickly. This could be a herculean task given the speed with which hacking technology is developing. One potential problem that could be faced by regulators is the issue of the ownership of the data generated by these technological developments. Is the data owned by 
the user or the service provider who stores it? If the latter owns the data, can these third parties be regulated by the authorities responsible for EA and regulation of mines? These are issues that have national implications and require broader government guidance and policies.

\subsection{IBAs and SEAs as markers of socio-economic benefits}

EA is designed not only to find ways to mitigate the negative impacts a project may have on the biophysical and human environments, but also to determine ways for projects to make positive contributions to the well-being of the biophysical and human environments [32]. In assessing the impacts of a project, the socio-economic benefits accruing to a community are important factors in the approval of a project. Hence the contents of the SEAs and at least, the presence of an IBA or variants of these agreements, are important markers for decision makers. With the disappearance of the jobs and contracting opportunities contained in SEAs and IBAs due to automation, what metric of socio-economic benefits should impact assessors and regulators assess in the EA process?

In northern Canada, Comprehensive Land Claims Agreements (CLCAs) require project proponents to enter into IBAs with potentially impacted communities. In such cases, the approval of a project in areas subject to the CLCAs is contingent partly on the negotiation of IBAs. Similarly, in the case of major projects, the contents of SEAs, could be considered during the project approval.

For impact assessors and other stakeholders, the question then becomes - if the content of these agreements become unachievable due to the impact of technological change, what kinds of socio-economic provisions replace those contained in the current IBAs and SEAs? Whatever options are considered, it is important that governments and potentially impacted communities continue to achieve shared value from mining [11].

\section{CONCLUSION}

Given the competitive nature of the mining sector, companies need to innovate to remain economically viable. Embracing technological innovation can result in reduced costs, increased productivity and improved worker safety for mining companies. However, to date, the industry's narrative has been focused on the upsides of new technologies, while remaining largely silent on the risks that these new technologies may pose for employees and members of potentially impacted communities. Mining technological innovations raise important questions about the relationship between mining companies and host communities. These include: what are the risks to host communities and to whom do they apply? Do the benefits of technological advancements to communities outweigh replace the benefits of traditional economic opportunities from mining? Without the direct economic benefits engraved in the IBAs and SEAs, will mining companies lose their social license to operate?

For most local communities, the primary benefits of mining are local jobs and procurement opportunities. However, it can be argued that the predicted acceleration in mine automation could disrupt the increasing trend of Aboriginal employment in the mining sector. Procurement opportunities for local Aboriginal companies may also decline due to automation. Fewer on-site opportunities will also reduce the spin-off benefits to local businesses such as in food services, accommodation, transportation, and recreation, that stem from population growth due to influx of workers.

Given that employment and procurements quotas form important components of IBAs and SEAs, technological innovation increases the likelihood that these agreements could be rendered ineffective. It can thus be argued that the net effect of automation would negatively impact the socioeconomic fabric of many Aboriginal communities. 
To mitigate some of the effects of automation, project proponents could refocus their attention on developing and maintaining local talent pools and supporting local participation in more automated, or technology-intensive jobs. IBAs and SEAs could be renegotiated to prioritise investments in science, technology, engineering, and math (STEM) education, at various levels. The provision of equity stakes to Aboriginal communities could be made a more prominent component of IBAs.

Technological innovation also has significant implications for the EA and regulatory processes. The lack of in-depth knowledge on the effects of these novel technologies on the environment and people could hamper the ability of authorities to accurately assess the risks associated with their deployment. This could potentially lead to a situation where projects are approved without adequate mitigatory measures in place. It is therefore pertinent for regulatory authorities to acquire the expertise needed to thoroughly assess the effects of these technologies. In cases where the expertise does not exist at all, there is a need for these authorities to collaborate with universities and other research networks to develop such knowledge base. For Aboriginal communities and final decision makers, the lack of information on the effects of these technologies potentially makes them reliant information provided by the project proponent.

The need for early engagement among all the relevant stakeholders (EA authorities, proponents, technology suppliers and communities) to enable all parties to gain an understanding of the effects of these technologies before they are deployed, cannot be underestimated. This would enable the authorities and communities to start their project assessment in a timely manner and seek responses to important questions about the technology, before the formal EA process commences. Organisations conducting impact assessments should institute nimble regulatory processes to respond to these emerging technological shifts.

While it may seem to some people that conversations around the automation of mines in northern Canada is premature or futuristic, it is worth noting that we have already witnessed the construction of digital mines in northern Ontario. Consequently, the earlier governments and communities begin discussing the future, the more chance there is of getting the policy settings pointing in sound directions.

\section{ACKNOWLEDGEMENTS}

This article would not have been possible without the support of the Department of Lands, Government of Northwest Territories, who paid for my participation in this conference and also allocated time for me to complete this paper. I owe an enormous debt of gratitude to Melissa Pink, my manager, who gave me detailed and constructive comments on the article and Lorraine Seale, my director, for providing the motivation and guidance during the writing process. Lastly, I thank my daughter Fatima, for putting up with me during the arduous process of writing the article.

\section{REFERENCES}

[1] Deloitte, Innovation state of play 2015. Toronto: Deloitte, Doblin and the Prospectors and Developers Association of Canada (PDAC). www2.deloitte.com/content/dam/Deloitte/ca/Documents/energy-resources/ Innovation_State_of_Play.PDF. Accessed on: 11 Feb. 2020.

[2] Delphi Group, Establishing technology leadership in the Canadian natural resources sector through industry-wide collaboration 2017. Delphi Group: Toronto.

[3] World Economic Forum (WEF), Digital transformation initiative: Mining and metals industry (White Paper). World Economic Forum: Geneva, p. 36, 2017. 
[4] International Institute for Sustainable Development (IISD), Innovation in mining: report to the 2018 International Mines Ministers Summit. IISD: Winnipeg, p. 28, 2018.

[5] Rio Tinto, Pioneering automation and robotics in mining 2020. www.riotinto.com/en/ about/innovation/automation. Accessed on: 13 Feb. 2020.

[6] Motion Metrics, How digital technologies are transforming the mining industry 2019. www.motionmetrics.com/connected-mine/how-digital-technologies-are-transforming -the-mining-industry/. Accessed on: 5 Feb. 2020.

[7] Gleeson, D., Why the Pilbara leads the way in haul truck automation 2019. https://im-mining.com/2019/08/06/pilbara-leads-way-haul-truck-automation/. Accessed on: 11 Feb. 2020.

[8] US Environmental Protection Agency (US EPA), National Center for Environmental Assessment, Office of Research and Development, Health assessment document for diesel engine exhaust 2002. US EPA: Washington, DC.

[9] Malmgren, I., Quantifying the societal benefits of electric vehicles. World Electric Vehicle Journal, 8, pp. 2032-6653, 2016.

[10] Arangio, S., Official opening of Canada's first all-electric mine. Northern Ontario CTV News, 24 Sep. 2019. https://northernontario.ctvnews.ca/official-opening-ofcanada-s-first-all-electric-mine-northern-ontario-1.4607600. Accessed on: 12 Feb. 2020.

[11] Cosbey, A., Mann, H., Maennling, N., Toledano, P., Geipel, J. \& Brauch, M.D., Mining a mirage? Reassessing the shared-value paradigm in light of the technological advances in the mining sector. International Institute for Sustainable Development (IISD): Winnipeg, p. 67, 2016.

[12] Natural Resources Canada, Mineral and Metals Section, (NRCan MMS), Canada's minerals and metals industry: An economic overview. Ottawa: NRCan, 2001.

[13] Rhéaume, G. \& Caron-Vuotari, M., The future of mining in Canada's North. The Conference Board of Canada, Centre for the North: Ottawa, 2013.

[14] Natural Resources Canada (NRCan), 10 key facts on Canada's minerals sector 2019, p. 1. www.nrcan.gc.ca/maps-tools-publications/publications/minerals-miningpublications/10-key-facts-canadas-minerals-sector/18423. Accessed on: 10 Feb. 2020.

[15] Natural Resources Canada (NRCan), Aboriginal participation in mining: Statistical profile 2009, catalogue no. M34-6/2-2009E-PDF. www.miningnorth.com/_rsc/sitecontent/library/stats-09-eng.pdf. Accessed on: 22 Feb. 2020.

[16] Holcombea, S. \& Kemp, D., Indigenous peoples and mine automation: An issues paper. Res. Policy, 63, p. 101420, 2019.

[17] Statistics Canada, Labour force characteristics by region and detailed Aboriginal group, Table 14-10-0365-01 2020. Statistics Canada: Ottawa. www150.statcan.gc.ca/t1/tbl1/en/tv.action?pid=1410036501. Accessed on: 23 Feb. 2020.

[18] Northwest Territories Statistics Bureau, NewsStats, Labour force activity 2020. Yellowknife: Northwest Territories Statistics Bureau. www.statsnwt.ca/labourincome/labour-force-activity/Monthly/Dec2019_NewStats\%20LFS.pdf. Accessed on: 20 Feb. 2020.

[19] Ramdoo, I., New tech, new deal: Technology impacts review 2019. International Institute for Sustainable Development, Intergovernmental Forum on Mining, Minerals, Metals and Sustainable Development: Winnipeg. www.igfmining.org/wpcontent/uploads/2019/10/new-tech-new-deal-technology.pdf. Accessed on: 20 Feb. 2020 . 
[20] Arriagada, P. \& Hango, D., Literacy and numeracy among off-reserve First Nations people and Métis: Do higher skill levels improve labour market outcomes? Insights on Canadian Society 2016, catalogue no. 75-006-X ISSN 2291-0840. Statistics Canada: Ottawa. Www150.statcan.gc.ca/n1/en/pub/75-006-x/2016001/article/14630eng.pdf?st=1WatkgDR. Accessed on: 22 Feb. 2020.

[21] Hitch, M., Impact and benefit agreements and the political economy of mineral development in Nunavut. Unpublished $\mathrm{PhD}$ thesis, University of Waterloo: Ontario, p. 249, 2006.

[22] Fidler, C. \& Hitch, M., Impact and benefit agreements: A contentious issue for environmental and Aboriginal justice. Env. Jour., 35(2), pp. 45-69, 2007.

[23] Natural Resources Canada (NRCan), Indigenous mining agreements 2018. NRCan Lands and Minerals Sector: Ottawa. https://atlas.gc.ca/imaema/en/index.html. Accessed on: 22 Feb. 2020.

[24] Government of Northwest Territories (GNWT), Socio-economic agreement report for diamond mines operating in the Northwest Territories 2018. GNWT: Yellowknife. www.iti.gov.nt.ca/sites/iti/files/socio-economic_agreement_report_-_2018.pdf. Accessed on: 22 Feb. 2020.

[25] Meerveld, D., Assessing value: A comprehensive study of impact benefit agreements on indigenous communities of Canada. University of Ottawa: Ottawa, p. 32, 2016.

[26] Alaska Structures, The advance of technology and methods of future mining operations. https://alaskastructures.com/mining/advances-in-mining-technologymethods/. Accessed on: 16 Feb. 2020.

[27] Impact Assessment Agency of Canada, Basics of environmental assessment 2019. Impact Assessment Agency of Canada: Ottawa. www.canada.ca/en/impactassessment-agency/services/environmental-assessments/basics-environmentalassessment.html\#gen01. Accessed on: 30 Jan. 2020.

[28] Eggers, W.D., Turley, M. \& Kishnani, P., The future of regulation. Principles for regulating emerging technologies. Deloitte Center for Government Insights: Arlington, VA, p. 20, 2018. www2.deloitte.com/us/en/insights/industry/public-sector/future-ofregulation/regulating-emerging-technology.html. Accessed on: 31 Jan. 2020.

[29] Mandel, G.N., Emerging technology governance. Innovative Governance Models for Emerging Technologies, eds G.E. Marchant, K.W. Abbott, J.E. Brown, \& B. Allenby. Edward Elgar Publishing Inc.: Cheltenham, pp. 44-62, 2013.

[30] Hischier, R., Life cycle assessment of manufactured nanomaterials: Inventory modelling rules and application example. Int J Life Cycle Assess, 19, pp. 941-943, 2014.

[31] Ponce Del Castillo, A.M., Nanomaterials and workplace health \& safety. What are the issues for workers? European Trade Union Institute, p. 44, 2013.) www.etui.org/Publications2/Gui+des/Nanomaterials-and-workplace-health-safety.What-are-the-issues-for-workers. Accessed on: 4 Feb. 2020.

[32] Noble, B.F., Introduction to Environmental Impact Assessment: A Guide to Principles and Practice. Oxford University Press: Don Mills, Ontario, 2010. 